\title{
The effects of loneliness and social isolation on all-cause, injury, cancer, and CVD mortality in a cohort of middle-aged Finnish men. A prospective study.
}

Siiri-Liisi Kraav* 1,2, Olutosin Awoyemi ${ }^{1,3,4}$, Niina Junttila ${ }^{5}$, Riitta Vornanen ${ }^{2}$, Jussi Kauhanen ${ }^{6}$, Timo Toikko ${ }^{2}$, Soili M. Lehto ${ }^{7,8,9}$, Sari Hantunen ${ }^{6}$, and Tommi Tolmunen ${ }^{1,10}$

${ }^{1}$ Institute of Clinical Medicine / Psychiatry, University of Eastern Finland, Kuopio, Finland ${ }^{2}$ Department of Social Sciences, University of Eastern Finland, Kuopio, Finland

${ }^{3}$ Coventry and Warwickshire Partnership NHS Trust, United Kingdom

${ }^{4}$ Department of Psychiatry, Kuopio University Hospital, Kuopio, Finland

${ }^{5}$ Department for Teacher Education, Centre for Education and Research on Social and Health Services, University of Turku, Finland.

${ }^{6}$ Institute of Public Health and Clinical Nutrition, University of Eastern Finland, Kuopio, Finland

${ }^{7}$ Institute of Clinical Medicine, University of Oslo, Oslo, Norway

${ }^{8} R \& D$ department, Division of Mental Health Services, Akershus University Hospital, Lørenskog, Norway

${ }^{9}$ Department of Psychiatry, University of Helsinki, Helsinki, Finland

${ }^{10}$ Department of Adolescent Psychiatry, Kuopio University Hospital, Kuopio, Finland

* Corresponding author information:

Siiri-Liisi Kraav, MSc

Institute of Clinical Medicine / Psychiatry,

University of Eastern Finland,

Yliopistonranta 1,

FIN-70210 Kuopio, Finland

E-mail: siiril@student.uef.fi, telephone: +358 40152 7167, twitter: @siiriliisi 


\section{The effects of loneliness and social isolation on all-cause, injury, cancer, and CVD mortality in a cohort of middle-aged Finnish men. A prospective study.}

Objectives: Loneliness and social isolation both increase mortality and are likely to affect health via several pathways. However, information on the potential pathways remains scarce. We investigated the associations between loneliness, social isolation, and mortality, and possible mechanisms underlying these connections.

Methods: The analyzed data comprised a prospective population-based cohort of Finnish men (42-61 years at baseline, $\mathrm{n}=2588)$ who were followed up for an average of 23.2 years. Mortality data were obtained from the national population register in 2012. Cox proportional hazards analysis with adjustments for possible confounding factors was used to examine the associations between loneliness and social isolation at baseline and all-cause, injury, cancer, and cardiovascular disease (CVD) mortality. Mediation analysis was conducted to investigate the mechanisms underlying the associations of loneliness and social isolation with mortality.

Results: Loneliness predicted all-cause mortality, even after adjustments for all covariates. Loneliness predicted cancer mortality, except after adjustments for lifestyle variables or Human Population Laboratory (HPL) depression scores, and also predicted CVD mortality, except after adjustments for HPL depression scores. Social isolation predicted all-cause mortality and injury mortality. The effect of social isolation on all-cause mortality was mediated by loneliness and HPL depression scores.

Conclusions: Our findings suggest that both loneliness and social isolation increase the risk of all-cause mortality, while they have differing effects on different causes of death. Loneliness and depressive symptoms may mediate the effect of social isolation on increased mortality.

Keywords: all-cause mortality, loneliness, social isolation, mediation, depression, longitudinal study. 


\section{Introduction}

The health risks associated with loneliness and social isolation may be comparable with wellestablished risk factors for mortality, such as smoking cigarettes and obesity (Holt-Lunstad et al., 2015; Valtorta et al., 2016). While the term loneliness focuses on the subjective perspective of social relationships, social isolation refers to the objective lack of social contacts with other people. Loneliness is the negative perception of social isolation, or the subjective experience of being lonely. Loneliness has also been described as dissatisfaction with the discrepancy between desired and actual social relationships (Weiss, 1974; Perlman \& Peplau, 1981). Loneliness and social isolation are independent constructs, and previous research has demonstrated a low correlation between them (Cornwell \& Waite, 2009; Coyle \& Dugan, 2012).

There are discrepant findings regarding whether social isolation is more predictive of mortality than loneliness. Current evidence suggests they may both equally contribute to the increased risk of mortality (Holt-Lunstad et al., 2015). Therefore, it has been proposed that loneliness and social isolation should be examined simultaneously (Cornwell \& Waite, 2009; Shankar et al., 2011). Furthermore, previous studies have mostly reported loneliness and social isolation as categorical variables, even though binary measures have been found less predictive of the mortality risk than more complex measures (Holt-Lunstad et al., 2010). Finally, previous studies have typically involved older adults (mean age of 66 years) and rather short follow-up periods (mean duration 7.1 years) (Holt-Lunstad et al., 2015). 
Previous studies have suggested different pathways through which loneliness and social isolation may impact on health. A large cross-sectional follow-up study in Finland (Tanskanen \& Anttila, 2016) concluded that loneliness and social isolation have their own separate, independent pathways to mortality. However, despite efforts to explore the mechanisms underlying the association between loneliness or social isolation and adverse health effects, there is no clear understanding of the causal pathways through which loneliness and social isolation affect human mortality and morbidity. Health behaviors, such as smoking and lack of exercise (Shankar et al., 2011), and physiological changes, such as increased blood pressure (Hawkley \& Cacioppo, 2010), may modify these connections. Recently, gender has been reported to contribute to the effect of loneliness and social isolation on mortality (Henriksen et al., 2019; Holwerda et al., 2014; Holwerda et al., 2016), .

Depression has also been suggested to be one of the possible pathways that lead from loneliness and social isolation to an increased incidence of cardiovascular diseases (CVD) and other diseases (Valtorta et al., 2018, Harasemiw et al., 2019). In addition, depression has been identified among the factors that may increase the risk of mortality in lonely and socially isolated people (Holwerda et al., 2016). Recently, a bidirectional connection between loneliness and depression has been suggested; lonely individuals are more likely to develop maladaptive behaviors, which in turn increase the feeling of loneliness (Dahlberg et al., 2018).

In the current study, we analyzed the connections between mortality and loneliness and social isolation as continuous variables in a sample of middle-aged men (42-61 years) with a long 
follow-up period of 23.2 years. We aimed to 1) investigate whether both loneliness and social isolation increase all-cause mortality, 2) analyze the effects of loneliness and social isolation on injury, cancer, and CVD mortality, 3) examine the effects of lifestyle as well as physiological changes and psychiatric symptoms on these associations, and 4) further explore the mechanisms underlying the connections between loneliness, social isolation, depression, and mortality through mediation analysis.

\section{Methods}

\section{Sample}

The Kuopio Ischaemic Heart Disease Risk Factor (KIHD) Study is an ongoing study designed to investigate the risk factors and outcomes of chronic diseases. The participants were a randomly selected, age stratified sample of general population men from Eastern Finland (Salonen, 1996). The participants were recruited between 1984 and 1989. All, except mortality variables were obtained from baseline measurements. The total sample consisted of 2682 participants. To avoid reversed causality (Holt-Lunstad et al., 2015; Liu \& Floud, 2017), individuals who had been diagnosed with cancer at baseline $(\mathrm{N}=51)$ and those who died within two years after baseline data collection $(\mathrm{N}=45)$ were excluded from the analysis. The final sample consisted of 2588 men aged $42-61$ years at baseline. All procedures were in accordance with the ethical standards of the institutional and national research committee and with the 1964 Declaration of Helsinki and its later amendments or comparable ethical standards and were approved by the Research Ethics Committee of the University of Kuopio. All the participants provided written informed consent. 


\section{Variables}

Outcome Variables: All-cause, Injury, Cancer, and CVD Mortality

Information on all-cause, injury, cancer, and CVD mortality was obtained by computer linkage to the national death registry by using the Finnish personal identification code. The analysis reported here included data on deaths that occurred before December 2011. Participants were followed up for a median of 23.2 years. All outcome variables were categorical. Injury, cancer, and CVD mortality were classified under ICD-10 codes S00-Z99, C00-C97 and I00-I99, respectively.

\section{Measurements of Loneliness and Social Isolation}

The KIHD Study questionnaires have an extensive range of questions that measure social relationships (Kaplan et al., 1994). In this analysis, we used two separate scales composed of available variables: the Loneliness Scale and the Social Isolation Scale. Details of the questions and coding for both scales are presented in Table 1. The Loneliness Scale consists of 11 items that measure the discrepancy between actual and desired social contacts (Perlman \& Peplau, 1981), subjective satisfaction with one's social life, and feelings of loneliness. The response options for questions in this scale were originally either binary or on a Likert scale. In order to balance the impact of different questions, all of them were recoded on a scale from 0 to 6 . Higher scores on the loneliness scale indicate higher levels of loneliness, the maximum score being 66 and the minimum score 0. Cronbach's alpha for the loneliness scale was 0.730 . The 
Social Isolation Scale consists of 10 items that measure the number of social contacts of the respondent. The scale is comprised of multi-categorical questions and questions for which the response indicates the number of times an event had occurred. For example, the frequency of occurrence of some events could be up to 100 times during a year. Therefore, in order to balance the impact of the number of different events, these responses were recoded on a scale from 0 to 4 (on two occasions from 0 to 2). Higher scores indicate higher levels of social isolation, the maximum score being 28 and the minimum score 0. Cronbach's alpha for the Social Isolation scale was 0.665 .

\section{Covariates}

\section{Questionnaire-based Variables}

Subjects were defined as smokers if they reported having ever smoked on a regular basis (Salonen et al., 1992). Alcohol consumption was assessed by using a structured quantityfrequency method with a drinking behavior questionnaire covering the previous 12 months (Ihanainen et al., 1989). The energy expenditure resulting from conditioning leisure time physical activities was assessed by using a 12-month history modified from the Minnesota Leisure Time Physical Activity Questionnaire. The intensity of physical activity was measured in metabolic units (metabolic equivalent of task (MET) or metabolic equivalent of oxygen uptake), with one MET being equivalent to an energy expenditure of approximately 1 $\mathrm{kcal} / \mathrm{kg} *$ hour and oxygen consumption of $3.5 \mathrm{ml} / \mathrm{kg} *$ minute. Energy expenditure expressed in $\mathrm{kcal} /$ week for each activity was estimated by multiplying the metabolic index of the activity (MET * hour/week) by the body weight in kilograms (Lakka et al., 1996). 
Depressive symptoms were assessed at baseline with the 18-item Human Population Laboratory (HPL) Depression Scale, which was especially developed for screening general population samples (Kaplan et al., 1987; Tolmunen et al., 2003; Tolmunen et al., 2004; Tolmunen et al., 2010). In order to avoid multicollinearity, we modified the depression scale for the analyses in this article and removed two items concerning loneliness ('I feel lonely or remote from other people' and 'Social withdrawal even from people I am close to'). Various measures of socioeconomic status (SES) were available from questionnaires completed as part of the baseline examination, including occupation, income, housing tenure, and ownership of material goods (Lynch et al., 1997). These variables were used to calculate an SES score.

The Baltic Sea Diet Score (BSDS) is a measure of adherence to the healthy Nordic diet, which consists of foods typically produced in the Nordic countries (Kanerva et al., 2014). The score is used in public health surveys in Nordic countries. Higher score values reflect greater adherence to the Baltic Sea diet (Kanerva et al., 2014). In the current analyses, slightly modified BSD scores (Tertsunen et al., 2020) were calculated based on four-day food records collected at baseline. In the analysis, the score was used as a continuous variable.

\section{Somatic Variables}

Systolic blood pressure was measured using a random-zero mercury sphygmomanometer.

Blood pressure was estimated by taking the mean of six measurements: three in a supine 
position, one standing, and two sitting (Lakka et al., 2002). Low density lipoprotein (LDL) portions were extracted from fresh serum by a method combining ultracentrifugation and precipitation during the medical examination (Lakka et al., 2002). Body mass index (BMI) was recorded as the weight in kilograms divided by the square of the height in meters. A history of CVD was defined as having a diagnosis of CVD other than high blood pressure. An estimate of the average number of hours slept at night was obtained using selfadministered questionnaires. High-sensitivity C-reactive protein (hs-CRP) was measured with an immunometric assay, the Immulite high-sensitivity CRP assay (Diagnostic Products Corporation, Los Angeles, California, USA), which has been standardized against the World Health Organization (WHO) international reference standard for CRP immunoassay, standard $85 / 506$.

\section{Statistical Methods}

According to Little's MCAR test, the missing data were observed to be missing completely at random (chi-squared $=814.141, \mathrm{p}=0.832$ ). For this article, we used two different ways to substitute missing values. Firstly, multiple imputation (MI) techniques were applied. In the imputation model, we used all the variables that were included in analyses. Altogether, $26 \%$ of cases had at least one missing value and 26 datasets were therefore created (White et al., 2011) with 20 iterations for each dataset. We included outcome variables in the model as predictors in order to increase the reliability of the imputation results (Moons et al., 2006). Due to using register-based data, we did not have any missing values for outcome variables. The MI dataset was used for all except the mediation analyses. The PROCESS macro for SPSS does not function with MI datasets, and for this step we therefore used the expectation maximization 
(EM) algorithm. There were essentially no differences between MI and EM datasets regarding descriptive statistics for any variables used in this article (data not shown).

Group differences in the categorical variables were analyzed with the chi-squared test, while the Student's t-test was used in comparisons of normally distributed variables and the nonparametric Mann-Whitney U test in comparisons of other continuous variables. The correlations between the variables were examined with Spearman's rank correlation coefficient.

Cox proportional hazards analysis (method: Enter) was used to examine the association between mortality, loneliness, and social isolation. To increase the comparability of the effects of loneliness and social isolation, we used their mean centered values (z-scores). The variables for adjustments were chosen based on their possible influence on life expectancy or their connection to loneliness and social relationships. Altogether, nine models were constructed: Model 1 was adjusted for age in years and year of examination; Model 2 was adjusted for age, year of examination, and SES in adulthood; Model 3 was adjusted age, year of examination, and lifestyle variables (alcohol consumption, smoking, and physical activity); Model 4 was adjusted for age, year of examination, and BSDS; Model 5 was adjusted for age, year of examination, and hours slept at night; Model 6 was adjusted for age, year of examination, and HPL depression scores; Model 7 was adjusted for age, year of examination, and hs-CRP; Model 8 was adjusted for age, year of examination, and physiological variables (systolic blood pressure, LDL cholesterol, BMI, and CVD history); and Model 9 was adjusted for all of the above-described variables (age, year of examination, SES, alcohol consumption, 
smoking and physical activity, BSDS, hours slept at night, HPL depression score, hs-CRP, low-density lipoprotein cholesterol, history of ischemic heart disease, and systolic blood pressure). The proportional hazard assumption was checked by plotting residuals against the follow-up time. These residuals were randomly distributed without any trends. To test the effect of marital or cohabitation status on all-cause mortality, we removed single men $(\mathrm{N}=$ 504) from the dataset and repeated the main analyses (Cox proportional hazard analyses, model 1 and model 9).

In mediation analyses, a good theory can establish a probable causal flow through which the antecedent variable (social isolation) transmits its effect on the consequent variable (all-cause mortality). The causal order of mediators inherently establishes that the cause precedes the effect in time (Hayes, 2018). Based on previous literature, we tested two alternative causal flows (Social isolation $\rightarrow$ HPL depression scores $\rightarrow$ Loneliness Scale scores $\rightarrow$ all-cause mortality vs. Social isolation $\rightarrow$ Loneliness Scale scores $\rightarrow$ HPL depression scores $\rightarrow$ allcause mortality). The mediation analysis was performed with the conditional modeling program PROCESS macro v.3.3 for SPSS (Hayes, 2018). For all mediation analyses, 5,000 bootstrap samples were used. If the upper and lower bounds of $95 \%$ percentile confidence intervals did not contain zero, the indirect effect was considered significant. P-values below 0.05 were considered to indicate statistical significance. All analyses were conducted using IBM SPSS (version 25) statistical software.

\section{Results}


The background characteristics of the participants are presented in Table 2 . The participants who died during the follow-up period were older than those who survived. They led an unhealthier lifestyle, were more depressed, had a lower SES, and were less healthy. Furthermore, those who died during the follow-up period had higher scores on both loneliness and social isolation scales than the men who survived.

There was a weak but significant positive correlation between scores on the loneliness and social isolation scales. Loneliness correlated positively with HPL depression scores, age, alcohol use, and Hs-CRP, and negatively with SES, exercise, sleep, and BSDS. Social isolation correlated positively with HPL depression scores, and negatively with SES, BSDS, age, physical exercise, BMI, and sleeping (Table 3).

In the multivariate models, both loneliness (Table 4) and social isolation (Table 5) were associated with all-cause mortality. These associations remained significant after adjustments for all the selected covariates (age, lifestyle variables (i.e., alcohol consumption, smoking, and physical activity), HPL depression scores, SES, hs-CRP, physiological variables, hours slept at night, and BSDS). We further explored whether the loneliness or social isolation scales differently predicted mortality in respect of injury, cancer, and CVD mortality. The results regarding loneliness and CVD mortality were significant, except when adjusted for HPL depression scores or all covariates at the same time. Social isolation was associated with increased injury mortality, except when adjusted for all covariates at the same time. Finally, in order to test whether loneliness and social isolation were independently associated with mortality, we added both loneliness and social isolation to the same, fully adjusted model. 
The results remained essentially the same (for loneliness, $\mathrm{HR}=1.09,95 \% \mathrm{CI}=1.02-1.16, \mathrm{p}$ $=0.010$; for social isolation, $\mathrm{HR}=1.07,95 \% \mathrm{CI}=1.00-1.14, \mathrm{p}=0.049)$.

To test the effect of cohabitation status on all-cause mortality, we repeated the main analyses after excluding the non-married, widowed, or divorced men $(\mathrm{N}=504)$. The results did not essentially differ from those for the full dataset (for loneliness scale model $1: H R=1.13$, 95\% CI $=1.06-1.21, \mathrm{p}<0.001 ;$ model 9: $\mathrm{HR}=1.10,95 \% \mathrm{CI}=1.02-1.19, \mathrm{p}=0.014$; for social isolation scale model $1: \mathrm{HR}=1.14,95 \% \mathrm{CI}=1.06-1.22, \mathrm{p}<0.001 ;$ model 9: $\mathrm{HR}=$ $1.10,95 \% \mathrm{CI}=1.03-1.18, \mathrm{p}=0.006)$.

In the first, parallel mediation model (Figure 1), we simultaneously inserted HPL depression scores and Loneliness Scale scores as mediators for the effect of social isolation on all-cause mortality. High scores in social isolation predicted higher HPL depression scores and higher Loneliness Scale scores. However, only HPL depression scores predicted all-cause mortality in this model. Secondly, in order to test the direction of pathways, we inserted the same mediators into the serial mediation model. When HPL depression scores were the first, and Loneliness Scale scores the second mediator (Figure 2), the effect of social isolation on allcause mortality was mediated by HPL depression scores only. There was a strong positive connection between HPL depression scores and Loneliness Scale scores, but the effect of social isolation on all-cause mortality was not mediated by Loneliness Scale scores. In the third model (Figure 3), where Loneliness Scale scores were inserted in the model as the first and HPL depression scores as the second mediator, the effect of social isolation on all-cause mortality was mediated by both loneliness and depression. 


\section{Discussion}

\section{Main Findings}

In the multivariate models, both loneliness and social isolation associated with all-cause mortality. When loneliness and social isolation were entered simultaneously into the same model with all the covariates, they both independently associated with all-cause mortality. Among injury, cancer, and CVD mortality, the results were significant regarding loneliness and CVD mortality. However, this association did not remain significant after adjustment for HPL depression scores. Social isolation was associated with injury mortality, except after adjustment for all the covariates at the same time.

The effect of social isolation on all-cause mortality was mediated by HPL depression scores. When loneliness was placed in the serial mediation model as the first and HPL depression scores as the second mediator, the effect of social isolation on all-cause mortality was mediated by both of these mediators. When the order of the mediators was reversed, the effect was mediated by HPL depression scores only, even though there was a strong positive connection between HPL depression scores and Loneliness Scale scores.

\section{Effect of Loneliness and Social Isolation on All-cause, Injury, Cancer, and CVD Mortality}

In general, our results regarding the connection between all-cause mortality and loneliness, as well as all-cause mortality and social isolation, reflect previous similar findings recently 
reviewed in the meta-analyses of Holt-Lunstad et al. (2015) and Rico-Uribe et al. (2018). While abundant research has examined the effects of loneliness and social isolation on allcause mortality, considerably fewer studies have further investigated injury, cancer, and CVD mortality in this context. To our knowledge, an increased risk of CVD mortality in socially isolated people has so far only been reported once (Tillmann et al., 2017). Previously, Julsing et al. (2016) reported no independent associations between moderate or severe loneliness and the risk of all-cause or CVD mortality. Further research is also needed on the associations between loneliness, social isolation, and cancer (Leigh-Hunt et al., 2017). While previous studies have examined the connection between cancer morbidity and both loneliness and social isolation, to the best of our knowledge, no reports have been published concerning cancer mortality. In our study, the association between loneliness and cancer mortality disappeared when adjusted for lifestyle variables, HPL depression scale scores, or all variables at the same time. Furthermore, loneliness increased the risk CVD mortality, while there was no connection with social isolation. In contrast, we observed an association between injury mortality and social isolation, while there was no clear association between injury mortality and loneliness. A connection between frequent falls, perceived social isolation, and social disconnectedness has been reported by Quach and Burr (2020). Moreover, they found that depression mediated this connection. Our observation supports the theory that loneliness and social isolation have different mechanisms through which they affect mortality. In other words, differences in these mechanisms might also logically be reflected by different associations with different causes of death.

\section{Relationship Between Loneliness and Social Isolation}


Previous studies have reported differing results concerning whether loneliness, social isolation, or both increase the risk of mortality or different diseases. Currently, there is insufficient evidence to suggest that one of these involves more risk than the other (HoltLunstad et al., 2015; Valtorta et al., 2016). We found that both loneliness and social isolation are connected to an increased risk of all-cause mortality. When loneliness and social isolation were entered into the same model with all the covariates, they both remained significant predictors of all-cause mortality, thus indicating that they independently predict all-cause mortality. Loneliness, however, was not directly the mediator for the effect social isolation has on all-cause mortality.

\section{Effects of Lifestyle and Physiological Changes}

Wang et al. (2020) followed up the oldest of the old for ten years and did not find an association between loneliness and mortality after controlling for health variables. For younger samples, however, loneliness and social isolation have been noted to affect health through their effects on health behaviors (Shankar et al., 2011), such as smoking, lack of exercise, or sleeping problems (Patterson \& Veenstra, 2010; Matthews et al., 2017). Social isolation may also affect health through increases in blood pressure and inflammatory processes (Shankar et al., 2011). Shankar et al. (2011) observed a small positive correlation between both CRP and fibrinogen levels and social isolation scores, but not loneliness scores. There is also evidence of metabolic dysregulation amongst older adults in association with loneliness (Shiovitz-Ezra \& Parag, 2019) and social isolation (Yang et al., 2013). However, in our data, none of the covariates concerning lifestyle, physiological changes, or metabolic or inflammatory status essentially reduced the significance of the effects of loneliness or social isolation on all-cause mortality. In the case of different causes of death, the association 
between loneliness and CVD mortality lost its significance when controlling for HPL depression scale scores, while cancer mortality also lost its significance when controlling for lifestyle variables.

\section{Depression}

The effect of social isolation, loneliness, and depression on all-cause mortality is complex, and these variables are interconnected. There have been discrepant hypotheses and findings regarding the relationship between depression, loneliness, and social isolation. In the 1980s, many clinicians believed that loneliness is simply an aspect of depression, and only later was it discovered that loneliness may be an independent risk factor for depression (Luanaigh \& Lawlor, 2008). Beutel et al. (2019) identified loneliness as one of the social factors that increase the risk of a new onset of depression in an aging population. Recently, a bidirectional connection between loneliness and depression has been suggested (Dahlberg et al., 2018). Park et al. (2017) found in a sample of older Korean Americans that loneliness acts as a mediator for the effect living alone has on depression. In contrast, McHugh Power et al. (2020) observed a unidirectional connection between depressive symptomatology and both emotional loneliness and social loneliness, both of which were predicted by, but did not predict, depressive symptoms. Depression is associated with loneliness (Eloranta et al., 2015; Dahlberg et al., 2018) and has been seen as a possible factor leading to higher rates of morbidity and mortality in lonely or socially isolated people (Patterson \& Veenstra, 2010).

In our data, loneliness was more strongly correlated with HPL depression scores than social isolation. Holwerda et al. (2016) found in a 19-year follow-up that severe depression was an 
important risk factor for death in men who were emotionally and socially lonely. Our results are in line with this previous study: in our parallel mediation model with HPL depression scores and Loneliness Scale scores as mediators, the effect of social isolation on all-cause mortality was mediated by depression, but not by loneliness. Furthermore, we wanted to explore whether depression mediates the effect of social isolation on loneliness (Park et al., 2017) or vice versa (McHugh Power et al., 2020). When entered into the serial mediation model, the direct effect of social isolation on all-cause mortality lost its significance, regardless of the order of mediators. In the model with loneliness as the first mediator and HPL depression scores as the second, there was one significant indirect path: the effect of social isolation on all-cause mortality was transmitted though Loneliness Scale scores and HPL depression scale scores. In the model in which HPL depression scale scores preceded Loneliness Scale scores, the effect of social isolation on all-cause mortality was mediated by HPL depression scale scores, but not by loneliness. However, there was a connection between loneliness and both social isolation and HPL depression scores. These observations suggest that in our data, there is a strong bidirectional connection between loneliness and depression. Our results are supportive of two alternative hypotheses, which may underline the previously suggested bidirectional relationship between loneliness and depression.

\section{Role of Marriage in Social Isolation}

Loneliness and social isolation have been found to be connected to the relationship status in both younger and older middle-aged adults (Child \& Lawton, 2019). A recent study compared the effect of social and emotional components of loneliness on mortality in the elderly and found that emotional loneliness is associated with higher mortality in older adults who are living alone (O'Súilleabháin et al., 2019). The group reporting the highest frequency 
of loneliness is unmarried males, indicating that marriage is somewhat protective against loneliness (Luanaigh \& Lawlor, 2008). Harasemiw et al. (2019) suggested that being unmarried increases the risk of depressive symptoms via lower support, especially lower affectionate support. To test the effect cohabitation status has on mortality, we repeated our main analyses after removing the non-married men from the dataset to test the role of marriage/cohabitation. The results were not essentially different from those for the whole dataset.

\section{Strengths and Limitations}

Our main strengths were a large and representative study sample with an opportunity to adjust our models for several possible confounding and mediating factors, including objective health indicators. We were also able to compare the effects of loneliness and social isolation on injury, cancer, and CVD mortality in the same sample, which is, to the best of our knowledge, a novel approach in this line of research. We used both loneliness and social isolation as continuous, dimensional variables, which added to the reliability of our findings. However, as loneliness and social isolation in our data were measured only once, there were no indicators of chronic loneliness and no information on changes in participants who lost their social network through the loss of friends or relatives, via the death of a spouse (Chirinos et al., 2019), or due to a change in living arrangements. Although loneliness among younger people has been shown to be a rather stable trait, in older people the risk of becoming lonely is higher (Newall et al., 2015). However, our results demonstrated the increased mortality risk for middle aged men who are lonely at baseline, and an additional growth in the frequency of loneliness that we were unable to measure would not decrease the significance of the results presented. Our sample comprises only middle-aged Finnish men, 
and the results cannot therefore be generalized to women or to other nationalities or age groups. In our data, loneliness and social isolation were both measured at baseline, and we were therefore unable to fully assess the causal relationships between them.

\section{Conclusions}

Our results demonstrated that loneliness and social isolation are interconnected, and part of the effect of social isolation on all-cause mortality is explained by the subjective feeling of loneliness. We found that depression was associated with and mediated the effect that social isolation has on all-cause mortality. We found a bidirectional connection between loneliness and depression. Further research on social isolation, loneliness, and depression is warranted. Our results underline the importance of increasing the availability of effective interventions for loneliness, as well as depression. Furthermore, in the light of our results, we consider it important to increase awareness among health care professionals of the differences between social isolation and loneliness and how they both influence the mental and physical health of patients.

Acknowledgements: The corresponding author was supported by the Signe and Ane Gyllenberg Foundation while writing this manuscript.

Disclosure of interest: The authors report no conflict of interest. 


\section{References}

Beutel, M. E., Brähler, E., Wiltink, J., Kerahrodi, J. G., Burghardt, J., Michal, M., et al. (2019). New onset of depression in aging women and men: Contributions of social, psychological, behavioral, and somatic predictors in the community. Psychological Medicine, 49(7), 1148-1155. doi:10.1017/S0033291718001848

Child, S. T., \& Lawton, L. (2019). Loneliness and social isolation among young and late middle-age adults: Associations with personal networks and social participation. Aging \& Mental Health, 23(2), 196-204. doi:10.1080/13607863.2017.1399345

Chirinos, D. A., Ong, J. C., Garcini, L. M., Alvarado, D., \& Fagundes, C. (2019).

Bereavement, self-reported sleep disturbances, and inflammation: Results from project HEART. Psychosomatic Medicine, 81(1), 67-73. doi:10.1097/PSY.0000000000000645

Cornwell, E. Y., \& Waite, L. J. (2009). Social disconnectedness, perceived isolation, and health among older adults. Journal of Health and Social Behavior, 50(1), 31-48. doi:10.1177/002214650905000103

Coyle, C. E., \& Dugan, E. (2012). Social isolation, loneliness and health among older adults. Journal of Aging and Health, 24(8), 1346-1363. doi:10.1177/0898264312460275

Dahlberg, L., Agahi, N., \& Lennartsson, C. (2018). Lonelier than ever? loneliness of older people over two decades. Archives of Gerontology and Geriatrics, 75, 96-103. doi:10.1016/j.archger.2017.11.004

Eloranta, S., Arve, S., Isoaho, H., Lehtonen, A., \& Viitanen, M. (2015). Loneliness of older people aged 70: A comparison of two finnish cohorts born 20 years apart. Archives of Gerontology and Geriatrics, 61(2), 254-260. doi:10.1016/j.archger.2015.06.004 
Harasemiw, O., Newall, N., Mackenzie, C. S., Shooshtari, S., \& Menec, V. (2019). Is the association between social network types, depressive symptoms and life satisfaction mediated by the perceived availability of social support? A cross-sectional analysis using the Canadian longitudinal study on aging. Aging \& Mental Health, 23(10), 1413-1422. doi:10.1080/13607863.2018.1495176

Hawkley, L., \& Cacioppo, J. (2010). Loneliness matters: A theoretical and empirical review of consequences and mechanisms. Annals of Behavioral Medicine, 40(2), 218-227. doi:10.1007/s12160-010-9210-8

Hayes, A. F., (2018). Introduction to mediation, moderation, and conditional process analysis: A regression-based approach. $2^{\text {nd }}$ ed. New York: Guilford Press

Henriksen, J., Larsen, E. R., Mattisson, C., \& Andersson, N. W. (2019). Loneliness, health and mortality. Epidemiology and Psychiatric Sciences, 28(2), 234-239. doi:10.1017/S2045796017000580

Holt-Lunstad, J., Smith, T. B., \& Layton, J. B. (2010). Social relationships and mortality risk: A meta-analytic review. PLoS Medicine, 7(7), e1000316. doi:10.1371/journal.pmed.1000316

Holt-Lunstad, J., Smith, T. B., Baker, M., Harris, T., \& Stephenson, D. (2015). Loneliness and social isolation as risk factors for mortality. Perspectives on Psychological Science, 10(2), 227-237. doi:10.1177/1745691614568352

Holwerda, T. J., Deeg, D. J. H., Beekman, A. T. F., van Tilburg, T. G., Stek, M. L., Jonker, C., et al. (2014). Feelings of loneliness, but not social isolation, predict dementia onset: Results from the amsterdam study of the elderly (AMSTEL). Journal of Neurology, Neurosurgery and Psychiatry, 85(2), 135-142. doi:10.1136/jnnp-2012-302755 
Holwerda, T. J., van Tilburg, T. G., Deeg, D. J. H., Schutter, N., Van, R., Dekker, J., et al. (2016). Impact of loneliness and depression on mortality: Results from the longitudinal ageing study amsterdam. The British Journal of Psychiatry, 209(2), 127-134. doi:10.1192/bjp.bp.115.168005

Ihanainen, M., Salonen, R., Salonen, J. T., \& Seppänen, R. (1989). Nutrition data collection in the kuopio ischaemic heart disease risk factor study: Nutrient intake of middle-aged eastern finnish men. Nutrition Research, 9(6), 597-604. doi:10.1016/S0271$5317(89) 80126-5$

Julsing, J. E., Kromhout, D., Geleijnse, J. M., \& Giltay, E. J. (2016). Loneliness and allcause, cardiovascular, and noncardiovascular mortality in older men: The zutphen elderly study doi://doi.org/10.1016/j.jagp.2016.01.136

Kanerva, N., Kaartinen, N. E., Schwab, U., Lahti-Koski, M., \& Männistö, S. (2014). The baltic sea diet score: A tool for assessing healthy eating in nordic countries. Public Health Nutrition, 17(8), 1697-1705. doi:10.1017/S1368980013002395

Kaplan, G. A., Roberts, R. E., Camacho, T. C., \& Coyne, J. C. (1987). Psychosocial predictors of depression. prospective evidence from the human population laboratory studies. American Journal of Epidemiology, 125(2), 206-220. doi:10.1093/oxfordjournals.aje.a114521 [doi]

Kaplan, G. A., Wilson, T. W., Cohen, R. D., Kauhanen, J., Wu, M., \& Salonen, J. T. (1994). Social functioning and overall mortality: Prospective evidence from the kuopio ischemic heart disease risk factor study. Epidemiology (Cambridge, Mass.), 5(5), 495-500. 
Lakka, H. M., Laaksonen, D. E., Lakka, T. A., Niskanen, L. K., Kumpusalo, E., Tuomilehto, J., et al. (2002). The metabolic syndrome and total and cardiovascular disease mortality in middle-aged men. Jama, 288(21), 2709-2716. doi:joc21220 [pii]

Lakka, T. A., Kauhanen, J., \& Salonen, J. T. (1996). Conditioning leisure time physical activity and cardiorespiratory fitness in sociodemographic groups of middle-ages men in eastern finland. International Journal of Epidemiology, 25(1), 86. Retrieved from MEDLINE database. Retrieved from https://www.ncbi.nlm.nih.gov/pubmed/8666509

Leigh-Hunt, N., Bagguley, D., Bash, K., Turner, V., Turnbull, S., Valtorta, N., et al. (2017). An overview of systematic reviews on the public health consequences of social isolation and loneliness. Public Health, 152, 157-171. doi:10.1016/j.puhe.2017.07.035

Liu, B., \& Floud, S. (2017). Unravelling the associations between social isolation, loneliness, and mortality. The Lancet Public Health, 2(6), e248-e249. doi:10.1016/S24682667(17)30090-7

Luanaigh, C. Ó., \& Lawlor, B. A. (2008). Loneliness and the health of older people. International Journal of Geriatric Psychiatry, 23(12), 1213-1221. doi:10.1002/gps.2054

Lynch, J. W., Kaplan, G. A., \& Shema, S. J. (1997). Cumulative impact of sustained economic hardship on physical, cognitive, psychological, and social functioning. The New England Journal of Medicine, 337(26), 1889-1895.

doi:10.1056/NEJM199712253372606

Matthews, T., Danese, A., Gregory, A. M., Caspi, A., Moffitt, T. E., \& Arseneault, L. (2017). Sleeping with one eye open: Loneliness and sleep quality in young adults. Psychological Medicine, 47(12), 2177-2186. doi:10.1017/S0033291717000629 
McHugh Power, J., Hannigan, C., Hyland, P., Brennan, S., Kee, F., \& Lawlor, B. A. (2020). Depressive symptoms predict increased social and emotional loneliness in older adults. Aging \& Mental Health, 24(1), 110-118. doi:10.1080/13607863.2018.1517728

Moons, K. G. M., Donders, R. A. R. T., Stijnen, T., \& Harrell, F. E. (2006). Using the outcome for imputation of missing predictor values was preferred.Journal of Clinical Epidemiology, 59(10), 1092-1101. doi:10.1016/j.jclinepi.2006.01.009

Newall, N., McArthur, J., \& Menec, V. H. (2015). A longitudinal examination of social participation, loneliness, and use of physician and hospital services. Journal of Aging and Health, 27(3), 500-518. doi:10.1177/0898264314552420

Park, N. S., Jang, Y., Lee, B. S., \& Chiriboga, D. A. (2017). The relation between living alone and depressive symptoms in older korean americans: Do feelings of loneliness mediate? Aging \& Mental Health, 21(3), 304-312. doi:10.1080/13607863.2015.1099035

Patterson, A. C., \& Veenstra, G. (2010). Loneliness and risk of mortality: A longitudinal investigation in alameda county, california. Social Science \& Medicine, 71(1), 181-186. doi:10.1016/j.socscimed.2010.03.024

Perlman, D., \& Peplau, L. A. (1981). Toward a social psychology of loneliness. In S. Duck, \& R. Gilmour (Eds.), Personal relationships: Personal relationships in disorder (pp. 278 pp). University of Michigan: Academic Press.

Quach, L. T., \& Burr, J. A. (2020). Perceived social isolation, social disconnectedness and falls: The mediating role of depression. Aging \& Mental Health, , 1-6. doi:10.1080/13607863.2020.1732294 
Rico-Uribe, L. A., Caballero, F. F., Martín-María, N., Cabello, M., Ayuso-Mateos, J. L., \& Miret, M. (2018). Association of loneliness with all-cause mortality: A metaanalysis. PloS One, 13(1), e0190033. doi:10.1371/journal.pone.0190033

Salonen, J. T. (1988). Is there a continuing need for longitudinal epidemiologic research? The Kuopio Ischaemic Heart Disease Risk Factor Study. Annals of Clinical Research, 20(12), 46-50.

Salonen, J. T., Nyyssonen, K., Korpela, H., Tuomilehto, J., Seppanen, R., \& Salonen, R. (1992). High stored iron levels are associated with excess risk of myocardial infarction in eastern finnish men. Circulation, 86(3), 803-811. doi:10.1161/01.cir.86.3.803 [doi]

Shankar, A., McMunn, A., Banks, J., \& Steptoe, A. (2011). Loneliness, social isolation, and behavioral and biological health indicators in older adults. Health Psychology : Official Journal of the Division of Health Psychology, American Psychological Association, 30(4), 377-385. doi:10.1037/a0022826

Shiovitz-Ezra, S., \& Parag, O. (2019). Does loneliness 'get under the skin'? associations of loneliness with subsequent change in inflammatory and metabolic markers. Aging \& Mental Health, 23(10), 1358-1366. doi:10.1080/13607863.2018.1488942

Tanskanen, J., \& Anttila, T. (2016). A prospective study of social isolation, loneliness, and mortality in finland. American Journal of Public Health, 106(11), 2042-2048. doi:10.2105/AJPH.2016.303431

Tertsunen, H. M., Hantunen, S., Tuomainen, T. P., \& Virtanen, J. K. (2020). Healthy nordic diet and risk of disease death among men: The kuopio ischaemic heart disease risk factor study. European Journal of Nutrition, doi:10.1007/s00394-020-02188-2 [doi] 
Tillmann, T., Pikhart, H., Peasey, A., Kubinova, R., Pajak, A., Tamosiunas, A., et al. (2017). Psychosocial and socioeconomic determinants of cardiovascular mortality in eastern europe: A multicentre prospective cohort study. PLoS Medicine, 14(12), e1002459. doi:10.1371/journal.pmed.1002459

Tolmunen, T., Hintikka, J., Ruusunen, A., Voutilainen, S., Tanskanen, A., Valkonen, V., et al. (2003). Dietary folate and the risk of depression in finnish middle-aged men. A prospective follow-up study. Psychotherapy and Psychosomatics, 73(6), 334.

Tolmunen, T., Hintikka, J., Voutilainen, S., Ruusunen, A., Alfthan, G., Nyyssonen, K., et al. (2004). Association between depressive symptoms and serum concentrations of homocysteine in men: A population study. The American Journal of Clinical Nutrition, 80(6), 1574-1578.

Tolmunen, T., Lehto, S. M., Heliste, M., Kurl, S., \& Kauhanen, J. (2010). Alexithymia is associated with increased cardiovascular mortality in middle-aged finnish men. Psychosomatic Medicine, 72(2), 187-191.

Valtorta, N. K., Kanaan, M., Gilbody, S., \& Hanratty, B. (2018). Loneliness, social isolation and risk of cardiovascular disease in the english longitudinal study of ageing. European Journal of Preventive Cardiology, 25(13), 1387-1396. doi:10.1177/2047487318792696

Valtorta, N. K., Kanaan, M., Gilbody, S., Ronzi, S., \& Hanratty, B. (2016). Loneliness and social isolation as risk factors for coronary heart disease and stroke: Systematic review and meta-analysis of longitudinal observational studies. Heart, 102(13), 1009-1016. doi:10.1136/heartjnl-2015-308790 
Wang, H., Leng, Y., Zhao, E., Fleming, J., \& Brayne, C. (2020). Mortality risk of loneliness in the oldest old over a 10-year follow-up. Aging \& Mental Health, 24(1), 35-40. doi:10.1080/13607863.2018.1510897

Weiss, R. S. (1974). Loneliness: The experience of emotional and social isolation The MIT Press.

White, I. R., Royston, P., \& Wood, A. M. (2011). Multiple imputation using chained equations: Issues and guidance for practice. Statistics in Medicine, 30(4), 377-399. doi:10.1002/sim.4067

Yang, Y. C., Li, T., \& Ji, Y. (2013). Impact of social integration on metabolic functions: Evidence from a nationally representative longitudinal study of US older adults. BMC Public Health, 13(1), 1210. doi:10.1186/1471-2458-13-1210 
Table 1.

Details of the Loneliness Scale and Social Isolation Scale

\section{Loneliness scale}

No one seems to understand my deepest feelings.

$($ Not true $=0 ;$ Can't say $=3 ;$ True $=6)$

At this very moment, do you feel lonely? (Not lonely at all $=0$; Can't say $=3$; Fairly lonely $=5$; Very lonely $=6$ )

How satisfied are you with the confidence and nearness of your relationships? (Very satisfied $=0$; Fairly satisfied $=1$; Fairly unsatisfied $=5$; Very unsatisfied $=6$ )

Even when I am with people, I very often feel lonely. $($ False $=0$; Can't say $=3$; True $=6)$

How do you feel when you think of your friends? (Very good $=0 ;$ Good $=1 ;$ Fairly good $=2$; Fairly miserable $=4$; Miserable $=5$; Very miserable $=6$ )

How do you feel when you think of your friendships and quantity of love? (Very good $=0$; Good $=1$; Fairly good $=2$; Fairly miserable $=4$; Miserable $=5$; Very miserable $=6$ )

Are you satisfied with the number of friends or relatives you can turn to when you need to borrow things like household objects or small amounts of money or need help with an errand? (Yes $=0 ;$ No $=$ 6)

Do you feel you have no true friends? $($ Yes $=6$; No $=$ 0 )

Are you satisfied with the number of friends and relatives to whom you can talk about your personal matters? $($ Yes $=0 ;$ No $=6)$

I feel that I don't have any real friends (Not true at all $=0$; Not very true $=1$; Fairly true $=5$; Completely true $=6$ )

I feel completely alone with my difficulties. (Not true at all $=0$; Not very true $=1$; Fairly true $=5$; Completely true $=6$ )

\section{Social isolation scale}

Cohabitation status $($ partner $=0 ;$ single $=2)$

How often do you go to meetings arranged by societies, clubs, or organizations? $(\geq 11=0 ; 1$ to $10=$ 1 ; Never $=2$ )

How many times did you visit your friends or relatives during the past month? $(\geq 5=0 ; 3$ to $4=1$; $2=2 ; 0$ to $1=3$ )

How many visits do you get from your friends or relatives during a month? $(\geq 9=0 ; 5$ to $8=1 ; 3$ to 4 $=2 ; 0$ to $2=3$ )

How often did you contact your closest friends by telephone or by letter during the past month? $(\geq 10=$ $0 ; 5$ to $9=1 ; 2$ to $4=2 ; 0$ to $1=3$ )

How many societies, clubs or organizations do you belong to? $(\geq 3=0 ; 2=1 ; 1=2 ; 0=3)$

How many times have you taken part in religious activities during the year? $(\geq 4=0 ; 2$ to $3=1 ; 1=2$; $0=3$ )

How many people could you be said to have friendly relations with? (Very many $=0$; Many $=1$; Some = 2 ; Very few $=3$ )

How many of your neighbors are you acquainted with? $(\geq 6=0 ; 4$ to $5=1 ; 2$ to $3=2 ; 0$ to $1=3)$

How many times did you celebrate at home or with your friends during the past 12 months? $(\geq 7=0 ; 3$ to $6=1 ; 1$ to $2=2 ; 0=3$ )
Minimum - 0, Maximum - 66

Higher scores indicate higher levels of loneliness.
Minimum - 0, Maximum - 28

Higher scores indicate higher levels of social isolation. 
Table 2.

Background Characteristics of the Study Population According to Death or Survival During the Follow-up.

\begin{tabular}{|c|c|c|c|c|}
\hline Variable & $\begin{array}{c}\text { Survived during } \\
\text { follow-up }(n=1456)\end{array}$ & $\begin{array}{c}\text { Deceased by } 2012 \\
(n=1132)\end{array}$ & Test value & P-value \\
\hline Age years, mean (SD) & $51.8(5.5)$ & $54.6(4.2)$ & -14.696 & $<0.001^{a}$ \\
\hline SES, mean (SD) & $13.71(5.1)$ & $11.46(4.9)$ & -11.297 & $<0.001^{a}$ \\
\hline Smoking, n (\%) & $339(23.3)$ & $491(43.4)$ & 118.006 & $<0.001^{c}$ \\
\hline Alcohol g/week & $25.3(5.24-80.08)$ & $39.81(6.61-119.87)$ & -5.075 & $<0.001^{\mathrm{b}}$ \\
\hline Physical activity (kcal/d) & $90(34-200)$ & $74(25-176)$ & -3.315 & $0.001^{b}$ \\
\hline Baltic Sea Diet Score & $13.25(3.9)$ & $12.23(4.1)$ & 6.387 & $<0.001^{\mathrm{a}}$ \\
\hline $\begin{array}{l}\text { Sleeping quantity, mean } \\
\text { (SD) }\end{array}$ & $2.84(1.6)$ & $2.93(1.8)$ & -1.274 & $0.203^{a}$ \\
\hline HPL depression scale & $1(0-2)$ & $1(0-3)$ & -5.300 & $<0.001^{b}$ \\
\hline Hs-CRP & $1.09(0.63-2.05)$ & $1.68(0.89-3.30)$ & -11.081 & $<0.001^{b}$ \\
\hline BMI, mean (SD) & $26.54(3.2)$ & $27.29(3.9)$ & -5.192 & $<0.001^{a}$ \\
\hline CVD history, n (\%) & $428(29.4)$ & $537(47.4)$ & 88.659 & $<0.001^{\mathrm{c}}$ \\
\hline $\begin{array}{l}\text { Systolic blood pressure, } \\
\text { mean (SD) }\end{array}$ & $132.03(15.6)$ & $136.93(18.4)$ & -7.133 & $<0.001^{a}$ \\
\hline LDL-C mmol/L, mean (SD) & $3.97(1.0)$ & $4.14(1.0)$ & -3.971 & $<0.001^{\mathrm{a}}$ \\
\hline Loneliness Scale & $12(8-19)$ & $13.12(8.04-23.9)$ & -4.327 & $<0.001^{b}$ \\
\hline $\begin{array}{l}\text { Social Isolation Scale, } \\
\text { mean (SD) }\end{array}$ & $12.97(5.1)$ & $13.58(5.1)$ & -2.997 & $0.003^{a}$ \\
\hline
\end{tabular}

Note. Values are medians (interquartile ranges), unless otherwise stated. $\mathrm{SD}=$ standard deviation; $\mathrm{SES}=$ socioeconomic status, BSDS = Baltic Sea Diet Scores, HPL = Human Population Laboratory, hs-CRP = high-sensitivity $\mathrm{C}$-reactive protein, $\mathrm{BMI}=$ body mass index, $\mathrm{CVD}=$ cardiovascular disease, $\mathrm{LDL}-\mathrm{C}=$ low density lipoprotein cholesterol.

${ }^{a}$ Student's t-test;

${ }^{\mathrm{b}}$ Mann-Whitney U test;

${ }^{\mathrm{c}}$ Chi-squared test 
Table 3.

Correlations Between the Continuous Variables Used in the Multivariate Models Measured

With Spearman's Rank Correlation Coefficients ( $p$-value)

\begin{tabular}{|c|c|c|c|c|c|c|c|c|c|c|c|c|}
\hline 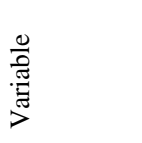 & 至 & $\begin{array}{l}\overline{0} \\
\frac{0}{0} \\
0 \\
\frac{0}{4}\end{array}$ & 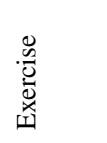 & 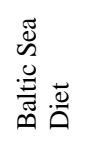 & $\frac{\bar{d}}{\frac{0}{n}}$ & 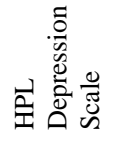 & $\begin{array}{l}\text { 究 } \\
\dot{1} \\
\text { 至 }\end{array}$ & $\hat{n}$ & 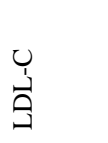 & $\sum_{n}$ & 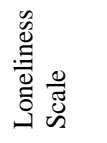 & 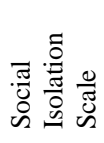 \\
\hline Age & $\begin{array}{l}-0.176, \\
<0.001\end{array}$ & $\begin{array}{l}-0.110, \\
<0.001\end{array}$ & $\begin{array}{l}-0.001 \text {, } \\
0.996\end{array}$ & $\begin{array}{l}0.077 \\
<0.001\end{array}$ & $\begin{array}{l}0.030 \\
0.131\end{array}$ & $\begin{array}{l}0.076 \\
<0.001\end{array}$ & $\begin{array}{l}0.076, \\
<0.001\end{array}$ & $\begin{array}{l}\text { 0.064, } \\
0.001\end{array}$ & $\begin{array}{l}\text { 0.046, } \\
0.021\end{array}$ & $\begin{array}{l}0.030 \\
0.124\end{array}$ & $\begin{array}{l}\text { 0.050, } \\
0.012\end{array}$ & $\begin{array}{l}-0.041, \\
0.035\end{array}$ \\
\hline SES & - & $\begin{array}{l}0.076 \\
<0.001\end{array}$ & $\begin{array}{l}0.148 \\
<0.001\end{array}$ & $\begin{array}{l}0.202 \\
<0.001\end{array}$ & $\begin{array}{l}-0.076 \\
<0.001\end{array}$ & $\begin{array}{l}-0.177 \\
<0.001\end{array}$ & $\begin{array}{l}-0.133 \\
<0.001\end{array}$ & $\begin{array}{l}-0.067, \\
0.001\end{array}$ & $\begin{array}{l}-0.130 \\
<0.000\end{array}$ & $\begin{array}{l}-0.033 \text {, } \\
0.096\end{array}$ & $\begin{array}{l}-0.140 \\
<0.001\end{array}$ & $\begin{array}{l}-0.103 \\
<0.001\end{array}$ \\
\hline Alcohol & & - & $\begin{array}{l}0.018 \\
0.353\end{array}$ & $\begin{array}{l}-0.128 \\
<0.001\end{array}$ & $\begin{array}{l}-0.020 \\
0.310\end{array}$ & $\begin{array}{l}0.050 \\
0.012\end{array}$ & $\begin{array}{l}0.101 \\
<0.001\end{array}$ & $\begin{array}{l}\text { 0.049, } \\
0.013\end{array}$ & $\begin{array}{l}0.032 \\
0.106\end{array}$ & $\begin{array}{l}0.088 \\
<0.001\end{array}$ & $\begin{array}{l}\text { 0.050, } \\
0.013\end{array}$ & $\begin{array}{l}-0.013, \\
0.459\end{array}$ \\
\hline Exercise & & & - & $\begin{array}{l}0.212 \\
<0.001\end{array}$ & $\begin{array}{l}-0.005 \text {, } \\
0.787\end{array}$ & $\begin{array}{l}-0.089 \\
<0.001\end{array}$ & $\begin{array}{l}-0.072 \\
<0.001\end{array}$ & $\begin{array}{l}0.010 \\
0.628\end{array}$ & $\begin{array}{l}-0.070 \\
<0.001\end{array}$ & $\begin{array}{l}-0.015 \\
0.460\end{array}$ & $\begin{array}{l}-0.053 \\
0.008\end{array}$ & $\begin{array}{l}-0.093 \\
<0.001\end{array}$ \\
\hline $\begin{array}{l}\text { Baltic Sea } \\
\text { Diet }\end{array}$ & & & & - & $\begin{array}{l}-0.014, \\
0.488\end{array}$ & $\begin{array}{l}-0.125 \\
<0.001\end{array}$ & $\begin{array}{l}-0.144, \\
<0.001\end{array}$ & $\begin{array}{l}-0.043 \\
0.029\end{array}$ & $\begin{array}{l}-0.103 \\
<0.001\end{array}$ & $\begin{array}{l}-0.006 \\
0.785\end{array}$ & $\begin{array}{l}-0.099 \\
<0.001\end{array}$ & $\begin{array}{l}-0.075 \\
<0.001\end{array}$ \\
\hline Sleep & & & & & - & $\begin{array}{l}-0.093 \\
<0.001\end{array}$ & $\begin{array}{l}0.038 \\
0.054\end{array}$ & $\begin{array}{l}0.002, \\
0.907\end{array}$ & $\begin{array}{l}0.055 \\
0.006\end{array}$ & $\begin{array}{l}0.030 \\
0.132\end{array}$ & $\begin{array}{l}-0.048, \\
0.018\end{array}$ & $\begin{array}{l}-0.056, \\
0.004\end{array}$ \\
\hline $\begin{array}{l}\text { HPL } \\
\text { Depression } \\
\text { Scale }\end{array}$ & & & & & & - & $\begin{array}{l}0.110 \\
<0.001\end{array}$ & $\begin{array}{l}0.018 \\
0.353\end{array}$ & $\begin{array}{l}-0.017 \text {, } \\
0.399\end{array}$ & $\begin{array}{l}0.059 \\
0.003\end{array}$ & $\begin{array}{l}0.420 \\
<0.001\end{array}$ & $\begin{array}{l}0.176 \\
<0.001\end{array}$ \\
\hline Hs-CRP & & & & & & & - & $\begin{array}{l}0.133 \\
<0.001\end{array}$ & $\begin{array}{l}0.071 \\
<0.001\end{array}$ & $\begin{array}{l}0.286 \\
<0.001\end{array}$ & $\begin{array}{l}\text { 0.057, } \\
0.004\end{array}$ & $\begin{array}{l}0.024 \\
0.223\end{array}$ \\
\hline BP & & & & & & & & - & $\begin{array}{l}\text { 0.042, } \\
0.034\end{array}$ & $\begin{array}{l}0.294 \\
<0.001\end{array}$ & $\begin{array}{l}-0.008, \\
0.701\end{array}$ & $\begin{array}{l}0.003 \\
0.879\end{array}$ \\
\hline LDL-C & & & & & & & & & - & $\begin{array}{l}-0.002, \\
0.913\end{array}$ & $\begin{array}{l}-0.021 \text {, } \\
0.300\end{array}$ & $\begin{array}{l}0.012 \\
0.564\end{array}$ \\
\hline BMI & & & & & & & & & & - & $\begin{array}{l}0.033, \\
0.105\end{array}$ & $\begin{array}{l}-0.056 \\
0.005\end{array}$ \\
\hline Loneliness & & & & & & & & & & & - & $\begin{array}{l}0.298 \\
<0.001\end{array}$ \\
\hline
\end{tabular}

Note. SES - socioeconomic status, HPL - Human Population Laboratory, hs-CRP - highsensitivity C-reactive protein, $\mathrm{BP}$ - mean systolic blood pressure, BMI - body mass index, CVD - cardiovascular disease, LDL-C - low-density lipoprotein cholesterol 
Table 4.

Hazard Ratios of Loneliness (Z-Score) for All-cause Mortality, Injury Mortality, Cancer Mortality, and CVD Mortality. Hazard ratios (95\% CI), P-Value.

\begin{tabular}{|c|c|c|c|c|}
\hline Model & All-cause mortality & Injury mortality & Cancer mortality & CVD mortality \\
\hline Model 1. & $\begin{array}{l}1.146(1.083-1.212) \\
p<0.001\end{array}$ & $\begin{array}{l}1.075(0.875-1.321) \\
p=0.490\end{array}$ & $\begin{array}{l}1.145(1.027-1.276), \\
p=0.015\end{array}$ & $\begin{array}{l}1.136(1.044-1.237) \\
p=0.003\end{array}$ \\
\hline Model 2. & $\begin{array}{l}1.124(1.062-1.191) \\
p<0.001\end{array}$ & $\begin{array}{l}1.049(0.851-1.293) \\
p=0.655\end{array}$ & $\begin{array}{l}1.129(1.012-1.260) \\
p=0.030\end{array}$ & $\begin{array}{l}1.114(1.022-1.214) \\
p=0.014\end{array}$ \\
\hline Model 3. & $\begin{array}{l}1.120(1.057-1.186) \\
p<0.001\end{array}$ & $\begin{array}{l}0.704(0.843-1.288) \\
p=0.704\end{array}$ & $\begin{array}{l}1.116(0.999-1.246) \\
p=0.051\end{array}$ & $\begin{array}{l}1.112(1.020-1.212) \\
p=0.015\end{array}$ \\
\hline Model 4. & $\begin{array}{l}1.132(1.069-1.198) \\
\text { p }<0.001\end{array}$ & $\begin{array}{l}1.069(0.869-1.315) \\
p=0.531\end{array}$ & $\begin{array}{l}1.123(1.006-1.254) \\
p=0.039\end{array}$ & $\begin{array}{l}1.124(1.032-1.225) \\
p=0.007\end{array}$ \\
\hline Model 5. & $\begin{array}{l}1.147(1.083-1.213) \\
p<0.001\end{array}$ & $\begin{array}{l}1.073(0.873-1.318) \\
p=0.504\end{array}$ & $\begin{array}{l}1.147(1.029-1.278), \\
p=0.014\end{array}$ & $\begin{array}{l}1.138(1.046-1.239) \\
p=0.003\end{array}$ \\
\hline Model 6. & $\begin{array}{l}1.079(1.079-1.010) \\
p=0.023\end{array}$ & $\begin{array}{l}0.972(0.763-1.237) \\
p=0.815\end{array}$ & $\begin{array}{l}1.101(0.970-1.249) \\
p=0.137\end{array}$ & $\begin{array}{l}1.069(0.970-1.179) \\
p=0.178\end{array}$ \\
\hline Model 7. & $\begin{array}{l}1.149(1.086-1.216) \\
p<0.001\end{array}$ & $\begin{array}{l}1.075(0.875-1.321) \\
p=0.492\end{array}$ & $\begin{array}{l}1.145(1.027-1.276), \\
p=0.015\end{array}$ & $\begin{array}{l}1.142(1.049-1.243) \\
p=0.002\end{array}$ \\
\hline Model 8. & $\begin{array}{l}1.146(1.083-1.214), \\
p<0.001\end{array}$ & $\begin{array}{l}1.073(0.873-1.317) \\
p=0.503\end{array}$ & $\begin{array}{l}1.142(1.024-1.274), \\
p=0.017\end{array}$ & $\begin{array}{l}1.139(1.045-1.241) \\
p=0.003\end{array}$ \\
\hline Model 9. & $\begin{array}{l}1.106(1.034-1.183) \\
p=0.003\end{array}$ & $\begin{array}{l}0.942(0.734-1.208) \\
p=0.636\end{array}$ & $\begin{array}{l}1.089(0.958-1.237) \\
p=0.194\end{array}$ & $\begin{array}{l}1.120(1.013-1.238), \\
p=0.028\end{array}$ \\
\hline
\end{tabular}

Note: Hazard ratios show the increase in the risk of mortality for each 1-SD increase in the Loneliness Scale score. Statistically significant results are bolded.

Model 1: Adjusted for age and year of examination

Model 2: Adjusted for age, year of examination, and adulthood socioeconomic status

Model 3: Adjusted for age, year of examination, and lifestyle variables (alcohol consumption, smoking, and physical activity)

Model 4: Adjusted for age, year of examination, and Baltic Sea Diet Score

Model 5: Adjusted for age, year of examination, and hours slept at night

Model 6: Adjusted for age, year of examination, and HPL depression scores

Model 7: Adjusted for age, year of examination, and hs-CRP

Model 8: Adjusted for age, year of examination, and physiological variables (systolic blood pressure, low-density lipoprotein cholesterol, body mass index, and past history of cardiovascular disease)

Model 9: Adjusted for all of the above-described variables. 
Table 5.

Hazard Ratios of Social Isolation (Z-Score) for All-Cause Mortality, Injury Mortality, Cancer Mortality, and CVD Mortality. Hazard Ratios (95\% CI), P-Value.

\begin{tabular}{|c|c|c|c|c|}
\hline Model & All-cause mortality & Injury mortality & Cancer mortality & CVD mortality \\
\hline Model 1. & $\begin{array}{l}1.133(1.069-1.201) \\
p<0.001\end{array}$ & $\begin{array}{l}1.284(1.039-1.586) \\
p=0.021\end{array}$ & $\begin{array}{l}1.126(1.005-1.262) \\
p=0.041\end{array}$ & $\begin{array}{l}1.099(1.008-1.198), \\
p=0.032\end{array}$ \\
\hline Model 2. & $\begin{array}{l}1.101(1.039-1.167) \\
p=0.001\end{array}$ & $\begin{array}{l}1.239(1.003-1.531) \\
p=0.046\end{array}$ & $\begin{array}{l}1.103(0.984-1.237) \\
p=0.092\end{array}$ & $\begin{array}{l}1.067(0.979-1.163) \\
p=0.140\end{array}$ \\
\hline Model 3. & $\begin{array}{l}1.112(1.079-1.146) \\
p<0.001\end{array}$ & $\begin{array}{l}1.261(1.130-1.407) \\
p=0.034\end{array}$ & $\begin{array}{l}1.098(1.036-1.164) \\
p=0.110\end{array}$ & $\begin{array}{l}1.081(1.034-1.129) \\
p=0.079\end{array}$ \\
\hline Model 4. & $\begin{array}{l}1.115(1.052-1.182) \\
p<0.001\end{array}$ & $\begin{array}{l}1.275(1.033-1.573) \\
p=0.025\end{array}$ & $\begin{array}{l}1.100(0.982-1.232) \\
\mathrm{p}=0.100\end{array}$ & $\begin{array}{l}1.084(0.995-1.181) \\
p=0.066\end{array}$ \\
\hline Model 5. & $\begin{array}{l}1.133(1.100-1.168) \\
p<0.001\end{array}$ & $\begin{array}{l}1.282(1.39-1.443) \\
p<001\end{array}$ & $\begin{array}{l}1.127(1.063-1.194), \\
p=0.039\end{array}$ & $\begin{array}{l}1.100(1.053-1.149), \\
p=0.031\end{array}$ \\
\hline Model 6. & $\begin{array}{l}1.101(1.037-1.168) \\
p=0.002\end{array}$ & $\begin{array}{l}1.242(1.057-1.460) \\
p=0.049\end{array}$ & $\begin{array}{l}1.101(0.981-1.237) \\
p=0.103\end{array}$ & $\begin{array}{l}1.068(0.978-1.165) \\
p=0.142\end{array}$ \\
\hline Model 7. & $\begin{array}{l}1.127(1.064-1.194) \\
p<0.001\end{array}$ & $\begin{array}{l}1.281(1.024-1.603) \\
p=0.022\end{array}$ & $\begin{array}{l}1.121(1.058-1.188), \\
p=0.048\end{array}$ & $\begin{array}{l}1.094(1.005-1.190), \\
p=0.040\end{array}$ \\
\hline Model 8. & $\begin{array}{l}1.135(1.072-1.202) \\
p<0.001\end{array}$ & $\begin{array}{l}1.289(1.157-1.437) \\
p=0.019\end{array}$ & $\begin{array}{l}1.129(1.063-1.199), \\
p=0.037\end{array}$ & $\begin{array}{l}1.100(1.010-1.198), \\
p=0.029\end{array}$ \\
\hline Model 9. & $\begin{array}{l}1.086(1.024-1.153) \\
p=0.006\end{array}$ & $\begin{array}{l}1.205(0.968-1.500) \\
p=0.097\end{array}$ & $\begin{array}{l}1.073(0.955-1.206) \\
\mathrm{p}=0.234\end{array}$ & $\begin{array}{l}1.063(0.974-1.159) \\
p=0.171\end{array}$ \\
\hline
\end{tabular}

Note: Hazard ratios show the increase in the risk of mortality for each 1-SD increase in the Loneliness Scale score. Statistically significant results are bolded.

Model 1: Adjusted for age and year of examination

Model 2: Adjusted for age, year of examination, and adulthood socioeconomic status

Model 3: Adjusted for age, year of examination, and lifestyle variables (alcohol consumption, smoking, and physical activity)

Model 4: Adjusted for age, year of examination, and Baltic Sea Diet Score

Model 5: Adjusted for age, year of examination, and hours slept at night

Model 6: Adjusted for age, year of examination, and HPL depression scores

Model 7: Adjusted for age, year of examination, and hs-CRP

Model 8: Adjusted for age, year of examination, and physiological variables (systolic blood pressure, low-density lipoprotein cholesterol, body mass index, and past history of cardiovascular disease)

Model 9: Adjusted for all of the above-described variables. 


\section{Figure 1.}

Loneliness Scale Scores and HPL Depression Scores Mediating the Effect of Social Isolation on All-Cause Mortality in a Parallel Mediation Model.

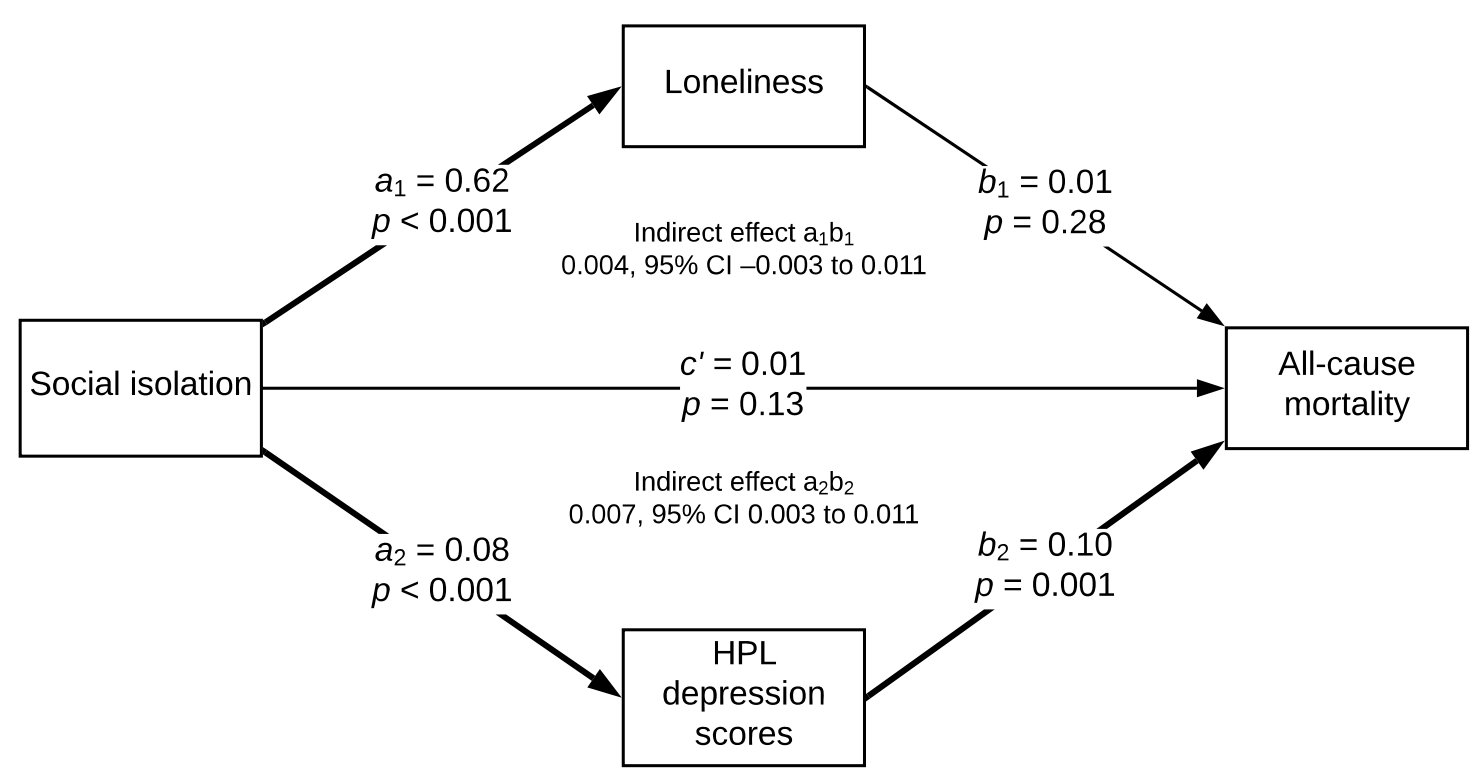




\section{Figure 2.}

Loneliness and HPL Depression Scores Mediating the Effect of Social Isolation on All-Cause Mortality in a Serial Mediation Model.

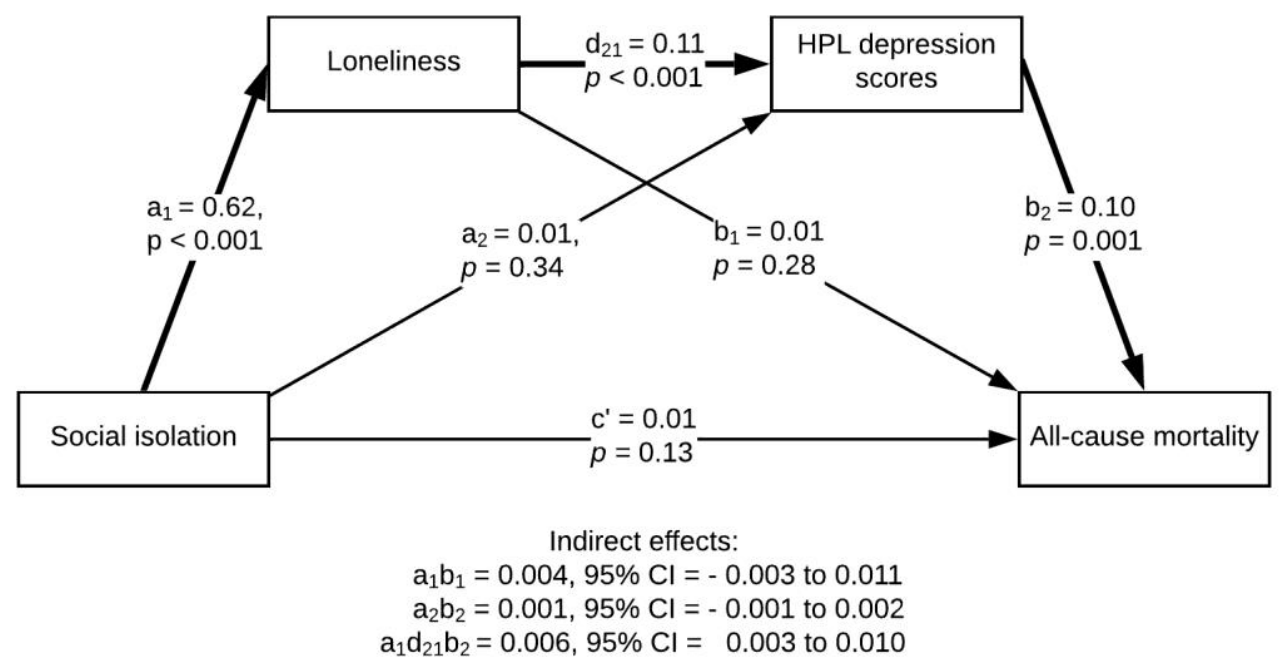




\section{Figure 3.}

HPL Depression Scale Scores and Loneliness Scale Scores Mediating the Effect of Social Isolation on All-Cause Mortality in a Serial Mediation Model.

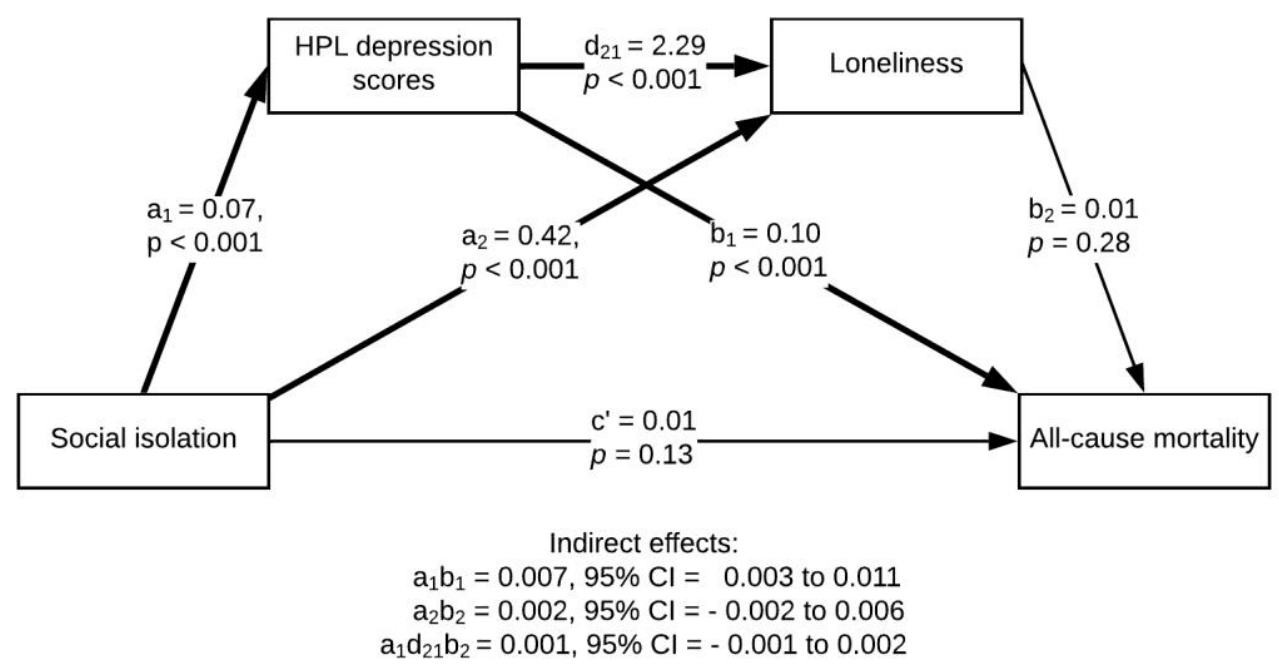

